\title{
Triptycene Copolymers as Proton Exchange Membrane for Fuel Cell - A Topical Review
}

\author{
How Hua Linga, Nurasyikin Misdan ${ }^{a, *}$, Farahiyah Mustafa ${ }^{a}$, Nur Hanis Hayati \\ Hairom $^{a}$, Rais Hanizam Madon ${ }^{a}$, Juhana, Jaafar ${ }^{b}$, Norhaniza Yusof ${ }^{b}$ \\ ${ }^{a}$ Faculty of Engineering Technology, Universiti Tun Hussein Onn Malaysia (UTHM), \\ 86400 Parit Raja, Batu Pahat, Malaysia; ${ }^{b}$ Advanced Membrane Technology Research \\ Centre (AMTEC), Universiti Teknologi Malaysia, 81310 Skudai, Johor, Malaysia
}

*For correspondence: nurasyikin@uthm.edu.my

Received: 11 March 2019 Accepted: 3 August 2021

(C) Copyright Hua Ling. This article is distributed under the terms of the Creative Commons Attribution License, which permits unrestricted use and redistribution provided that the original author and source are credited
Abstract In view of the pressing need for alternative clean energy source to displace the current dependence on fossil fuel, proton exchange membrane fuel cell (PEMFC) technology have received renewed research and development interest in the past decade. The electrolyte, which is the proton exchange membrane, is a critical component of the PEMFC and is specifically targeted for research efforts because of its high commercial cost that effectively hindered the widespread usage and competitiveness of the PEMFC technology. Much effort has been focused over the last five years towards the development of novel, durable, highly effective, commercially viable, and low-cost co-polymers as alternative for the expensive Nafion ${ }^{\circledR}$ proton exchange membrane, which is the current industry standard. Our primary review efforts will be directed upon the reported researches of alternative proton exchange membrane co-polymers which involved Triptycene derivatives. Triptycene derivatives, which contain three benzene rings in a three-dimensional non-compliant paddlewheel configuration, are attractive building blocks for the synthesis of proton exchange membranes because it increases the free volume in the polymer. The co-polymers considered in this review are based on hydrocarbon molecular structure, with Triptycene involved as a performance enhancer. Detailed herein are the development and current state of these co-polymers and their performance as alternative fuel cell electrolyte.

Keywords: Proton exchange membrane fuel cell, proton exchange membrane, Triptycene.

\section{Introduction}

A proton exchange membrane fuel cell (PEMFC) is essentially an energy converter that directly converts the chemical energy stored in the hydrogen fuel and oxygen into direct current electricity, with water and heat as the only byproducts. Generally, fuel cell technology has received considerable research attention from the scientific community since the beginning of the 21 st century because of the depleting fossil fuel resources available to humanity and our ever-increasing need for sustainable and environmentally friendly energy. However, the high cost required for the usage of PEMFCs has greatly limited their applications [1].

The scientific community has recently focusing on developing novel materials and fabrication processes to improve the PEMFCs and to optimize PEMFC for commercialization. The aim is to enable PEMFCs to compete with the conventional fossil fuel-based energy production technology. PEMFCs can be used as large-scale power generators such as in power plant application, and also as small-scale power generators such as automotive mobile engines and small stationary generators [2]. The PEMFCs generate electric power by electro-chemical reactions, which are as follows:

Anode: $2 \mathrm{H}_{2} \rightarrow 4 \mathrm{H}^{+}+4 \mathrm{e}^{-}$ 
Cathode: $\mathrm{O}_{2}+4 \mathrm{e}^{-}+4 \mathrm{H}^{+} \rightarrow 2 \mathrm{H}_{2} \mathrm{O}$

Cell reaction: $2 \mathrm{H}_{2}+\mathrm{O}_{2} \rightarrow 2 \mathrm{H}_{2} \mathrm{O}$

The positively charged hydrogen ions move from the anode to the cathode through the electrolyte of PEMFC. The PEMFCs' electrolyte is also known as the proton exchange membrane (PEM), and it is a critical component of PEMFCs. PEM also prevents electrons and fuel from flowing through it. The illustration of the PEMFC working theory is shown in Fig. 1 [3]. In 1964, DuPont Company produced PEMs called Nafion ${ }^{\circledR}$, which have polytetrafluoroethylene as the polymer backbone [4]. Since then, Nafion ${ }^{\circledR}$ have undergone tremendous improvements, with many variations produced. Till today, Nafion ${ }^{\circledR}$ is still going strong and used commercially because of its desired properties such as high proton conductivity and good thermal and chemical strength. Nafion ${ }^{\circledR}$ is even the industrial standard for PEM [5]. However, Nafion ${ }^{\circledR}$ do possess some weaknesses that seriously hamper its widespread usage, such as high production cost, high susceptibility to $\mathrm{CO}$, and serious reduction of proton conductivity at higher operating temperatures above $100^{\circ} \mathrm{C}$. Therefore, much research have been focused on developing PEM that is cheaper to produce, with better proton conductivity, lower fuel/water crossover, better thermal and chemical durability, stronger mechanical properties and longer functional lifetime [1].

Researchers have done much study and developed different types of PEMs through the functionalization of different polymeric materials, to achieve the best results for effective PEMFC application. Particularly, research interest on 'Triptycene for proton exchange membrane fuel cell application' has increased in recent years. This is because as more research on the synthesis of composite polymers of both fundamental and practical significance was done, Triptycene scaffold stands out among the rest of the monomers in terms of structural performance, due to its structural strength and rigidity, nonplanarity and bulkiness [11, 12]. The increase of such research interest is shown by the increase of the number of publications that relates to it on the world-renowned scientific literature platform SCOPUS ${ }^{\circledR}$, which is the largest abstract and citation database of peer-reviewed literature platform. This is shown in Fig. 2.

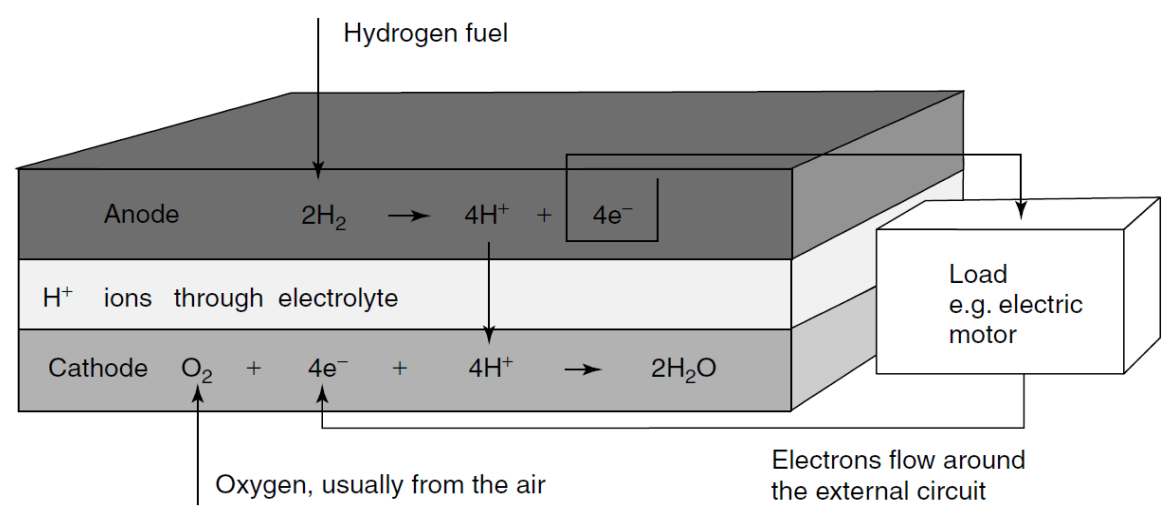

Fig. 1 The electro-chemical reactions of PEMFC and the charge flow involved [6].

The total number of published articles found for the year 2005 to 2018 in SCOPUS ${ }^{\circledR}$ on 10 th January 2019 was 102, which deal specifically with Triptycene.

\section{Influence of Triptycene in PEM for PEMFC applications}

Studies were done on improving PEM performance by developing and investigating the different types of composite membranes for PEM in PEMFC applications. These different types of composite membranes were developed by joining main polymer backbones with different types of pristine or functionalized filler particles such as silica, clays, metal oxides, triptycene, hetero-polyacids, and carbon nanotubes. These filler particles, imbedded as nanoparticles in composite membranes, are known to improve the proton conductivity, mechanical strength, and durability of the composite membranes for PEMFC applications [7].

The standout polymer backbones among the composite materials that were studied for PEM in PEMFC applications include 4,4'-biphenol (BPSH) and sulfonated composite polymers such as sulfonated 
poly(ether ether ketone) (SPEEK) and sulfonated poly(aryl ether sulfone) (SPAES). These mentioned sulfonated composite polymers were found to have good chemical resistance and high thermo-oxidative stability, with SPAES standing out due to its elevated glass transition temperature, strong mechanical properties, flexible processability, and wonderful hydrolytic stability [7]. Among the different types of pristine or functionalized filler particles studied for PEM in PEMFC applications, the basic Triptycene scaffold stands out among the rest in the synthesis of composite polymers of both fundamental and practical significance, because of its structural strength and rigidity, nonplanarity, bulkiness, and $\pi-$ electron richness. Basically, Triptycene is the simplest member of a unique class of compounds called Iptycenes, which are made of arenes that are fused together through the bicyclo[2.2.2]octane framework, with aromatic rings as bridges. The three-dimensional structure of Triptycenes creates a high degree of interstitial space (free volume) around it, as shown in Fig. 4. Triptycene groups are known to possess rigid, bulky, and highly hydrophobic structure [11, 12].

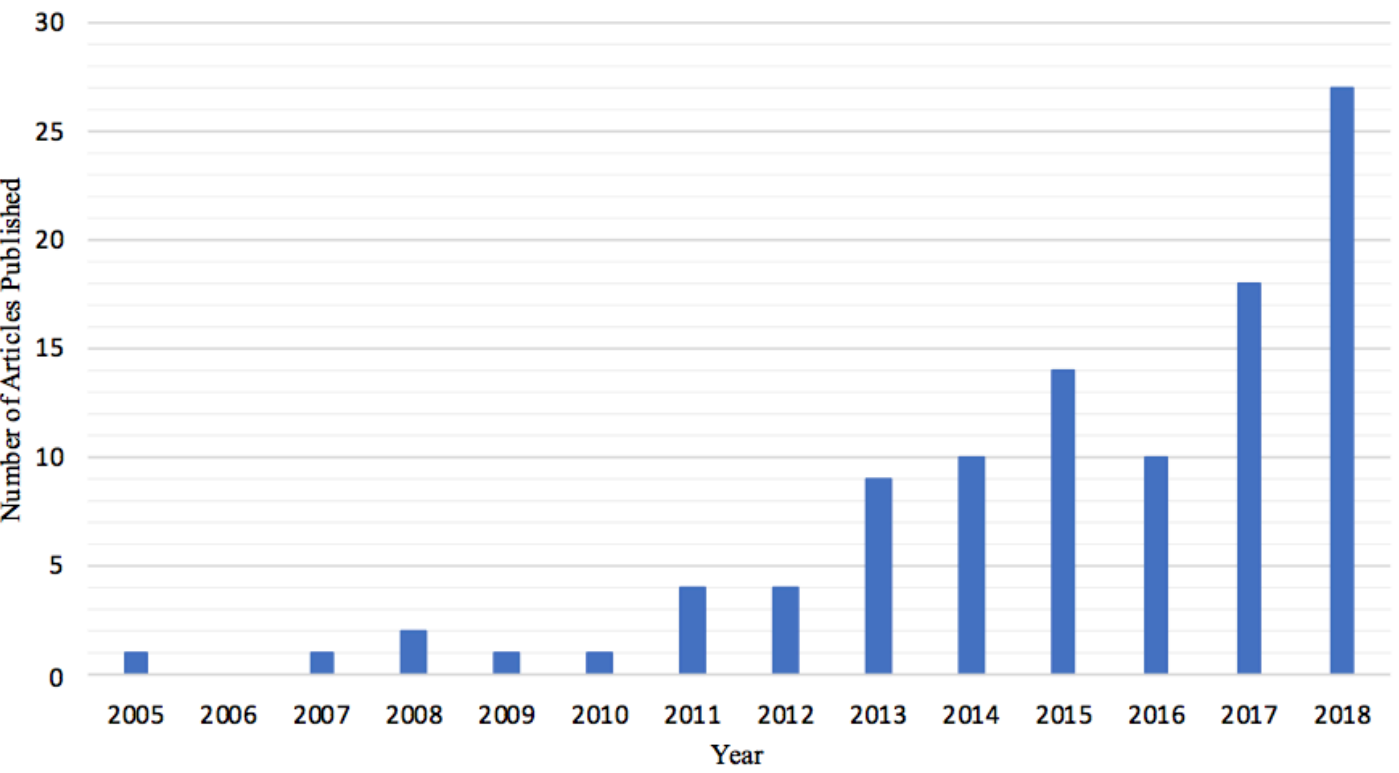

Fig. 2 Number of articles on triptycene for PEM application published per year (2005 to 2018) according to the SCOPUS $®$ database.

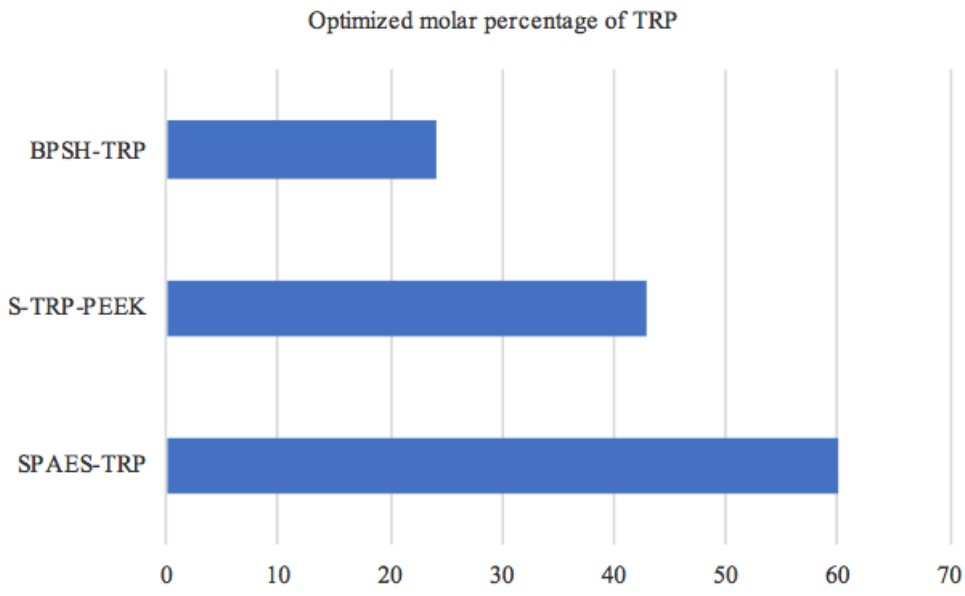

Fig. 3 Optimized molar percentage of Triptycene (TRP) in different composite polymer PEM for PEMFC applications [8-10]. 


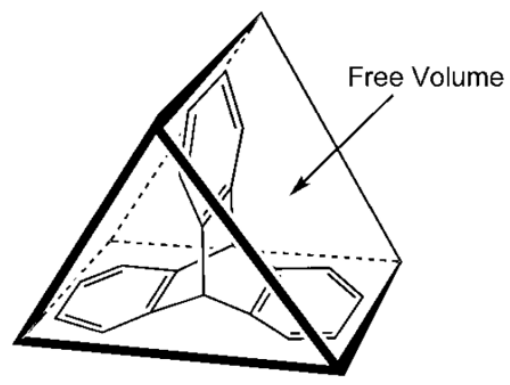

Fig. 4 Triptycene (TRP), inscribed in a trigonal prism to illustrate the free volume around it [11].

With such excellent qualities, Triptycene have attracted much research interest to incorporate Triptycene composite materials as electrolyte for different types of fuel cells, not merely for PEMFC. However, in this topical review paper, we will only discuss on the previous studies involving the implementation of Triptycene composite materials as PEM for PEMFC applications. Composite polymers that have Triptycene incorporated into the main polymer backbones have been studied and experimented in previous studies, and were observed to possess excellent thermal stability, chemical stability, porosity, mechanical strength, which are critical characteristics for PEMs [11]. Also, combining composite polymers with these Triptycene groups usually results in good water uptake and high proton conductivity even in low humidity [12].

In general, numerous types of both pristine and functionalized filler particles were studied to improve the fundamental properties of composite membranes for PEM in PEMFC applications. Here, we discuss only composite polymer backbones used with Triptycene particles as filler, such as poly(ether ether ketone) (PEEK), SPEEK, poly(arylene ether sulfone) (PAES), PAES and 4,4'-biphenol based fully disulfonated poly(arylene ether sulfone) hydrophilic oligomers (BPS100). The optimized molar percentages of Triptycene (TRP) filler in the different composite polymer backbones as PEM for PEMFC applications are shown in Fig. 3.

From Fig. 3, we can directly note that the optimum amount of TRP particles in molar percentage imbedded in the composite polymer BPS100 backbone as PEM for PEMFC application is $24 \%$. Also, $43 \%$ is the optimum amount, in molar percentage, of TRP particles imbedded in the composite polymer SPEEK backbone as PEM for PEMFC application. For the un-sulfonated composite polymer PEEK backbone as PEM for PEMFC application, the optimum amount, in molar percentage, of imbedded TRP particles is $55 \%$, which is slightly higher than its sulfonated counterpart SPEEK backbone. In the case of TRP particles imbedded in the composite polymer SPAES backbone as PEM for PEMFC application, the optimum amount, in molar percentage, of imbedded TRP particles is $60 \%$. For the un-sulfonated composite polymer PAES backbone as PEM for PEMFC application, the optimum amount, in molar percentage, of imbedded TRP particles is $23 \%$, which is much lower than its sulfonated counterpart SPAES backbone.

The optimal addition of TRP domains upon the composite back bone has a positively significant effect on the molecular morphology of the composite polymer membrane and its matrix. Another effect of optimizing the percentage of TRP is the entanglement of polymers and improved morphological stability, which causes very low swelling in water [13]. Also, it allows for better critical PEM properties, such as proton conductivity, water uptake, mechanical strength, and durability, which are required especially for hydrogen fuel cell applications. Detailed effects of the optimal addition of TRP domains upon each of the various composite polymer back bone studied will be discussed in this paper.

\section{TRP particles in multiblock copolymer containing 4,4'-biphenol (BPSH)}

The TRP containing multiblock copolymers, when compared to the previously reported multiblock copolymers which contain no such iptycene structures, exhibited excellent dimensional stability, with significantly lower water swelling ratios despite their comparably higher water uptake. The significantly reduced water swelling of these copolymers can be attributed to the unique supramolecular interactions induced by the TRP units in the hydrophobic sequences [8].

The membrane properties depict a very strong reliance on block length. While the water uptake and proton conductivity increased proportionally with block length as expected, a nonlinear dependence of water swelling on block length was observed due to the enhanced supramolecular interaction of TRP 
units in the copolymers with long block lengths. Unlike in other multiblock copolymer systems, the longer block lengths typically required to achieve large-scale morphological order did not result in excessive swelling of the TRP-containing PEM, but enhanced both its proton conductivity and membrane dimensional stability in hydrated conditions. Excessive water swelling of membranes tends to dilute the ion concentration, reduce the dimensional stability, and deteriorate the mechanical properties of the membranes $[14,15]$.

The obtained multiblock copolymer membranes also exhibited distinct nanophase separated morphology which was gradually developed with block length and responsible for their excellent proton conductivities and low swelling. Multiblock copolymer membranes with distinct nanophase separated morphology is considered as a solution to overcome the drawbacks of a random copolymer system [16]. The combination of low water swelling ratio and high proton conductivity suggest that these TRP-containing membranes have great potential for applications in PEMFC.

\section{TRP particles in multiblock copolymer containing Sulfonated Poly(Ether Ether Ketone) (SPEEK)}

Studies done upon S-TRP-PEEKs showed an initial mass loss that is associated with the loss of water that is attached to the hygroscopic sulfonate groups. The mass loss at $350{ }^{\circ} \mathrm{C}$ was attributed to the decomposition of sulfonate groups. Hence, S-TRP-PEEKs are considered stable up to $350{ }^{\circ} \mathrm{C}$, which is well above the normal operating temperature of up to $200^{\circ} \mathrm{C}$ in PEMFCs [9].

The skeletal densities of S-TRP-PEEKs also do not decrease with the increasing number of TRP groups. Calculations for the volume per repeat unit show elevated numbers with increasing ratios of TRP moiety in the polymer, suggesting that the fluctuations in skeletal density are the result of the increase in mass contributed from the bulky TRP groups. More importantly, the fractional free volume (FFV) was observed to increase with the number of TRP moiety in the polymer. Since the dimensions used to calculate FFV are the same ones used for the calculation in proton conductivity, FFV is directly related to the amount of space water molecules can occupy within the membrane, which in turn affects the proton conductivity of the membrane. Also, presence of frozen-in free volume allows the membranes to hold water tightly at low humidity [17].

Studies done on the S-TRP-PEEKs membranes clearly reveals that increases in FFV enhances proton conductivities, especially at low relative humidity. This enhancement of proton conductivity that correlates with FFV varies at different levels of relative humidity. At low humidity, when the water within the membrane is reduced, the increased free volume in the membrane allowed more water uptake within the S-TRP-PEEK membrane, which helps to maintain the hydration number at lower humidity, and hence the proton conductivity enhancement. Within the S-TRP-PEEK membrane, water aggregates around the hydrophilic sulfonate groups, solvating them to release protons. Thus, we can consider the sulfonate groups in the membrane as impurity in the water phase. At a smaller hydration number, there are more sulfonate groups with respect to water molecules in the membrane, resulting in a larger melting point depression of water in the membrane [9].

Activation energies at different levels of humidity were studied, which further illustrate the dependence on hydration number and improvements resulting from increasing intrinsic free volume in the membrane. Activation energies are a measure of the ease of proton transport in the membrane and are highly dependent on water uptake in the membrane [18]. S-TRP-PEEKs has a wide window of relative humidity wherein the activation energies for proton transport were low. More importantly, as the intrinsic free volume increases, the activation energies decreased across the whole range of humidity. This result suggests that intrinsic free volume enhances the ease of proton transport [9].

The inclusion of the TRP moiety into multiblock copolymer containing SPEEK adds steric bulk which prevents noncovalent attraction between aromatic rings and inhibits crystallization, which are observed in standalone SPEEK membranes. Differential Scanning Calorimetry (DSC) thermal analysis of TRPSPEEKs showed only a single glass transition and no melting transition, suggesting that TRP-PEEKs are random copolymers that do not crystallize. The absence of a crystalline phase makes TRP-SPEEKs more soluble than SPEEK and allows for solubility in common organic solvents, such as chloroform, dichloromethane, and boiling polar solvents, such as dimethylacetamide and dimethylformamide. With enhanced solubility, TRP-SPEEKs polymerizes to a high molecular weight which soluble fractions have a number average molecular weight of more than $100 \mathrm{kDa}$ with respect to polystyrene standards. High molecular weights in TRP-SPEEKs allow for good film forming properties that are necessary to form freestanding membranes [19].

In addition to enhanced solubility, TRP moieties also affect the density of the TRP-SPEEKs polymers. 
Since the TRP increases the free volume in the material, it was expected that with more of the TRP moiety present, the density will be lower. However, adding TRP moieties also increases the mass of repeating unit. By normalizing the densities with the average molecular weight of a repeating unit, the volume per mole of repeating unit shows that with more TRP in the polymer the higher the volume per repeat unit is obtained, suggesting that TRP can contribute to additional volume in each repeat unit [9].

\section{TRP particles in multiblock copolymer containing sulfonated Poly(Arylene Ether Sulphone) (SPAES)}

Studies on SPAES-TRP membranes were done and its thermal properties were analyzed by thermogravimetric analysis (TGA) in nitrogen atmosphere. The analysis revealed that the SPAES-TRP membranes exhibited a typical three-step degradation pattern at desirable temperatures, which revealed that the SPAES-TRP are thermally stable to fulfil the requirements of thermal stability for the use in PEMFCs. Good mechanical properties of the PEMs are one of the demands for PEMFC applications. The mechanical properties of the SPAES-TRP membranes were measured at room temperature and $60 \% \mathrm{RH}$. The SPAES-TRP membranes' stress-strain data showed the general trend of lower maximum stress for the membranes with higher IEC. The SPAES-TRP membranes exhibit suitable resistance against tensile stress. The tension results undoubtedly showed they were strong and flexible enough membranes for fuel cell application even at high sulfonation degree [10].

In order to investigate hydrophilic-hydrophobic microphase separation and the proton transport pathway of the SPAES-TRP membranes, transmission electron microscopic (TEM) observations were carried out. SPAES-TRP membranes exhibited hydrophilic domain that was large and the connectivity of hydrophilic domain increased with increasing sulfonation degree. It was reasonable that the hydrophilic aggregates became larger and the connectivity of hydrophilic domain increased as increasing IEC due to increased concentration of sulfonic acid groups. The sulfonic acid functional groups aggregate to form a hydrophilic domain. When this is hydrated, protonic charge carriers form within inner space charge layers by dissociation of the acidic functional groups, and proton conductance assisted by water dynamics occurs. Another is through the "Hopping" mechanism that takes place when sufficient water content is presented so that the side chains of sulfonic groups are connected, where protons can move directly from one site to another. While the well-connected hydrophilic domain is responsible for the transport of protons and water, the hydrophobic domain provides the polymer with the morphological stability and prevents the polymer from dissolving in water. Such hydrophobic/hydrophilic nano-separation of microstructure allows the effective proton transportation via the membrane, therefore, the membranes showed high proton conductivity in a wide range of humidity $[2,13]$.

The water content has a great effect on the properties of PEMs. For most proton conductive polymers, water acts as the carrier for proton transportation through the polymer membrane. Adequate hydration of electrolyte membranes is crucial for high proton conductivity. However, water swelling ratio should be also considered because extreme swelling will decrease the dimensional stability and mechanical properties of the polymer films. Controlling the degree of sulfonation is important because a high degree of sulfonation generally leads to high swelling [20]. The water uptake and swelling ratio data of SPAESTRP membranes were studied, and it was observed that an increase in IEC and temperature led to an increase in water uptake and swelling ratio. It is noteworthy that the SPAES-TRP membranes displayed low water uptake and swelling ratio at desirable IEC values under normal PEMFC operating temperatures and conditions [10].

The proton conductivities of SPAES-TRP membranes were studied, and it was observed that proton conductivities increased with IEC values and the number of water molecules per sulfonic acid unit. The ionomers with higher IEC showed significantly higher proton conductivity at low humidity. The excellent proton conduction of the SPAES-TRP membranes especially at low humidity may be explained by its excellent connectivity of proton paths and good water-holding capability of sulfonated TRP groups [10]. The influence of TRP on various multiblock copolymers and the amount of TRP on the performance of various multiblock copolymers are shown in Table 1.

\section{Fundamental properties of TRP-containing multiblock copolymer membranes}

Water uptake

In PEMFCs, the protons move forward through water channels and thus, water uptake of PEM has a significant impact on the membrane performance in terms of proton conductivity. An adequate water 
uptake is fundamental in sustaining high proton conductivity. As shown by the BPSH-TRP, the water uptake increased monotonically with increasing block length, which is a typical observation for multiblock copolymers since longer hydrophilic sequences are more effective in absorbing and binding water. The increase in the water uptake with increasing block length of the BPSH-TRP membranes suggest the formation of nanophase separated membrane morphology within. Since it is typically desirable to operate PEMFCs at $80^{\circ} \mathrm{C}$ or higher, the water uptake ratio was also measured at various temperatures. Water uptake of BPSH-TRP membranes were reported to increase with temperature. When temperature increased from $25^{\circ} \mathrm{C}$ to $80^{\circ} \mathrm{C}$, the BPSH-TRP membranes exhibited about $7 \%$ increase in water uptake, with $112 \%$ water uptake at $80^{\circ} \mathrm{C}$. This observation is caused by the supramolecular interactions induced by TRP units such as chain threading and interlocking in the hydrophobic sequences that improves membrane water uptake even at relatively high temperatures [8].

Table 1 Effect of optimized amount and preparation method of TRP in different multiblock copolymers for PEMFC.

\begin{tabular}{|c|c|c|c|}
\hline $\begin{array}{l}\text { Type of } \\
\text { Multiblock } \\
\text { Copolymer }\end{array}$ & $\begin{array}{l}\text { Optimized } \\
\text { molar fraction } \\
\text { of TRP (\%) }\end{array}$ & Preparation Method & Description \\
\hline BPSH-TRP & 24 & $\begin{array}{l}\text { Aromatic nucleophilic } \\
\text { substitution reaction }\end{array}$ & $\begin{array}{l}\text { The BPSH-TRP membrane containing } 24 \mathrm{M} \% \text { of TRP reported } \\
\text { enhanced proton conductivity and membrane dimensional stability } \\
\text { in hydrated conditions [8]. }\end{array}$ \\
\hline S-TRP-PEEK & 43 & $\begin{array}{l}\text { Sulfonation after } \\
\text { aromatic nucleophilic } \\
\text { substitution reaction }\end{array}$ & $\begin{array}{l}\text { The } 43 \mathrm{M} \% \text { of TRP in S-TRP-PEEK enhances proton conductivity, } \\
\text { especially at low relative humidity because of the increased free } \\
\text { volume in the membrane that allowed more water uptake [9]. }\end{array}$ \\
\hline SPAES-TRP & 60 & $\begin{array}{l}\text { Aromatic nucleophilic } \\
\text { substitution } \\
\text { polycondensation }\end{array}$ & $\begin{array}{l}\text { The SPAES-TRP membrane containing } 60 \mathrm{M} \% \text { of TRP reported } \\
\text { high IEC value and high proton conductivity at low RH and higher } \\
\text { temperature [10]. }\end{array}$ \\
\hline
\end{tabular}

At low relative humidity of just $20 \%$, S-TRP-PEEK showed amazing water uptake of $9.7 \%$. This is because even when the moisture within the S-TRP-PEEK membrane is low, the increased free volume in the membrane allowed more water uptake which helps to maintain the hydration number at lower humidity, and enhances the proton conductivity. Within the membrane, water aggregates around the hydrophilic sulfonate groups, solvating them to release protons [9].

The SPAES-TRP membranes, with high sulfonation degree, exhibited a relative rapid increase in water uptake at high temperature, attributed to the formation of large and continuous ion network in the sulfonated multiblock copolymers. The introduction of large conjugated TRP groups in SPAES increase the pi stacking, which is the attractive, noncovalent interactions between aromatic rings, between aromatic polymer chains. The SPAES-TRP also has sulfonic acid groups attached in side chain. Its structure, with TRP groups included, was assembled in a way to minimize free volume and fill the concave clefts of the triptycene groups, so the interlocking structure formed among the polymer main chains. Similarly, the interlocking structure could also be formed in the SPAES-TRP polymer main chain which prohibit the over-swollen of SPAES-TRP membranes due to water uptake [10].

\section{Mechanical and thermal properties}

The mechanical properties of the membrane are essential for the performance and durability as a PEM for PEMFC applications. The thermal stability of the membrane is also an important aspect so as to avoid operation failure that occurs due to the decomposition of the membrane [21]. Swelling of PEM due to water uptake may disrupt its connectivity with the electrodes. Thermogravimetric analysis (TGA) is used to measure the thermal decomposition profile of the membrane, which depends on factors such as the heating rate, gas (nitrogen or oxygen) flow rate, and sample preparation technique [7].

The BPSH-TRP membrane, despite their expectedly high water-uptake values, still displayed excellent dimensional stability with greatly reduced swelling ratios compared to the widely accepted industrial standard Nafion ${ }^{\circledR}$ membrane and other non-TRP containing PAES multiblock copolymers reported in the literature. The swelling ratio of the BPSH-TRP copolymers was reported to increase with temperature. 
When temperature increased from $25{ }^{\circ} \mathrm{C}$ to $80{ }^{\circ} \mathrm{C}$, the BPSH-TRP membranes exhibited about $21 \%$ increase in swelling ratio, with $50 \%$ swelling ratio at $80{ }^{\circ} \mathrm{C}$. This observation indicates that the strong supramolecular interactions introduced by the TRP units in the long hydrophobic sequences could effectively restrict and suppress water swelling via physical interlocking and possible chain threading mechanism [8].

The BPSH-TRP copolymer membranes in the fully hydrated state showed tensile strength of 17-30 MPa, Young's modulus of $0.37-0.72 \mathrm{GPa}$, and elongation at break of $6.4-10 \%$. When compared to $\mathrm{Nafion}^{\circledR}$ membrane, BPSH-TRP copolymer membranes showed higher tensile strength but smaller elongation at break. Although the long TRP-containing hydrophobic sequences are largely responsible for the increase in the stiffness and strength with block length, other factors such as the molecular weight of copolymers may also influence their mechanical properties. These data demonstrate that the BPSH-TRP copolymers yielded strong and flexible membranes, which are suitable for application as PEM materials. The thermal stabilities of the acid-form BPSH-TRP multiblock copolymer films were studied using TGA. The membranes showed a two-step weight loss behavior. The first noticeable weight loss occurred at around $271{ }^{\circ} \mathrm{C}$ and was attributed to the degradation of sulfonic acid groups. The second weight loss began at $\sim 503{ }^{\circ} \mathrm{C}$, and was ascribed to the main chain decomposition. These data demonstrate that the BPSHTRP copolymers membranes possessed higher thermal stability compared to Nafion ${ }^{\circledR}$ membranes [8]. TGA done on S-TRP-PEEK showed an initial mass loss as the membrane is heated up that is associated with the loss of water that is attached to the hygroscopic sulfonate groups. Right after the initial mass loss, a drastic mass loss was observed at $350^{\circ} \mathrm{C}$ which is attributed to the decomposition of sulfonate groups. Hence, S-TRP-PEEK can be considered as stable up to $350{ }^{\circ} \mathrm{C}$, which is well above the operating temperature of up to $200{ }^{\circ} \mathrm{C}$ in PEMFCs $[22,23]$.

Table 2 Proton conductivity of various TRP-containing copolymers membranes.

\begin{tabular}{ccccc}
\hline $\begin{array}{c}\text { Type of Multiblock } \\
\text { Copolymer }\end{array}$ & Temperature $\left({ }^{\circ} \mathrm{C}\right)$ & RH $(\%)$ & Proton conductivity $(\mathbf{m s} / \mathbf{c m})$ & Reference \\
\hline BPSH-TRP & 80 & 95 & 153.3 & {$[8]$} \\
S-TRP-PEEK & 85 & 90 & 334 & {$[9]$} \\
SPAES-TRP & 80 & 94 & 250 & {$[10]$} \\
Nafion $212^{\circledR}$ & 80 & 95 & 89.4 & {$[8]$} \\
\hline
\end{tabular}

However, at higher humidity, the enhanced water uptake of S-TRP-PEEK can lead to membrane swelling, which can isolate sulfonates and reduce the its conductivity enhancement. S-TRP-PEEK membranes were reported to swell by more than $200 \%$ in water and are soluble in water at temperatures above $50{ }^{\circ} \mathrm{C}$. The SPAES-TRP membranes, with high sulfonation degree, exhibited a relative rapid increase in swelling ratio at high temperature, attributed to the formation of large and continuous ion network in the sulfonated SPAES-TRP polymers. SPAES-TRP membranes exhibited swelling ratio of $26.7 \%$ at $20^{\circ} \mathrm{C}$ and $59.3 \%$ at $80^{\circ} \mathrm{C}$, which was much lower than PAES containing sulfofluorenyl groups under similar IEC value and conditions [9].

The low swelling ratio of SPAES-TRP membranes is attributed to the TRP groups which were introduced in the SPAES-TRP copolymers. The introduction of large conjugated TRP groups in SPAES increased the pi stacking between aromatic polymer chains so that the swelling ratio were confined [24]. The SPAES-TRP also has sulfonic acid groups attached in side chain. Its structure, with TRP groups included, was assembled in a way to minimize free volume and fill the concave clefts of the TRP groups, so the interlocking structure formed among the polymer main chains. Similarly, the interlocking structure could also be formed in the SPAES-TRP polymer main chain which prohibit the over-swollen of SPAESTRP membranes due to water uptake $[11,25]$.

Additionally, the thermal stability of the SPAES-TRP copolymers membranes was investigated by TGA in a nitrogen atmosphere. It was reported that the SPAES-TRP copolymers membranes exhibited a typical three-step degradation pattern. The first weight loss up to $150^{\circ} \mathrm{C}$ was ascribed to the loss of water molecules, absorbed by the highly hygroscopic- $\mathrm{SO}_{3} \mathrm{H}$ groups. The second weight loss around $300{ }^{\circ} \mathrm{C}$ was due to the cleavage of the sulfonic acid groups. The third stage weight loss of SPAES-TRP around $530^{\circ} \mathrm{C}$ was assigned the decomposition of polymer main chain. From these results, it can be concluded that the SPAES-TRP membranes are thermally stable to satisfy the requirement of thermal stability for 
the use as PEM in PEMFCs. The mechanical properties of the SPAES-TRP copolymers membranes were measured at room temperature and $60 \% \mathrm{RH}$. It was reported that the membranes have tensile stress at maximum load of 21.8-45.9 MPa and elongation at break of $10-38 \%$ with the general trend of lower maximum stress for the higher IEC membranes. The tension results undoubtedly showed they were strong and flexible enough membranes for fuel cell application even at high sulfonation degree [10].

Overall, when the TRP-containing copolymer is subjected to the strain from swelling, the interlocking interactions between the TRP units allow them to transfer the load from one polymer chain to another. The increased pi stacking interactions induced by the introduction of conjugated TRP units in the hydrophobic sequences also played a role in increasing structural stiffness and suppressing membrane swelling. As such, longer TRP-containing hydrophobic sequences with a higher concentration of triptycene units along the polymer backbone enhance the supramolecular interlocking interactions between the hydrophobic sequences and hence are more effective in suppressing membrane swelling. Such supramolecular effects were demonstrated in previous studies by Luo et al. [26], and Tsui et al. [27], that the effectiveness of molecular interlocking in withstanding an applied load depends on the concentration of iptycene units along the polymer chain [8].

\section{Proton conductivity}

Proton conductivity of PEM plays a crucial role in PEMFCs as it affects the migration of protons from the anode to the cathode through the PEM. It was reported that BPSH-TRP membranes' proton conductivity under $95 \% \mathrm{RH}$ at $80{ }^{\circ} \mathrm{C}$ was $153.3 \mathrm{mS} / \mathrm{cm}$, which is 1.7 times that of Nafion ${ }^{\circledR}(89.4 \mathrm{mS} / \mathrm{cm})$ measured under the same conditions. The enhanced proton conductivity is caused by the increased connectivity of the hydrophilic and ionic domains in the BPSH-TRP membranes, which reduced the energy barrier for ion transport. Ion transport was made easier by enhancing water diffusion which causes the reduction of morphological barrier [28]. The proton conductivities of the BPSH-TRP membranes multiblock copolymers also increased linearly with temperature and relative humidity. Also, it was found that the BPSH-TRP membranes' proton conductivity is dependent on the membrane hydration level, which effectively lowers the activation energy required for the transport of protons in the membranes. The supramolecular interactions induced by TRP units are advantageous in suppressing membrane swelling while retaining the favorable water uptake required for sustaining high proton conductivity in the membranes [8].

In another report, S-TRP-PEEK membranes at $20 \% \mathrm{RH}$ and $85^{\circ} \mathrm{C}$ have proton conductivities of 0.37 $\mathrm{mS} / \mathrm{cm}$, compared to Nafion ${ }^{\circledR}$ at $0.0014 \mathrm{mS} / \mathrm{cm}$ and SPEEK at $0.0015 \mathrm{mS} / \mathrm{cm}$. On the other hand, at $90 \%$ $\mathrm{RH}$, S-TRP-PEEK membranes exhibit proton conductivities of $334 \mathrm{mS} / \mathrm{cm}$, as compared to Nafion ${ }^{\circledR}$ at $20 \mathrm{mS} / \mathrm{cm}$ and SPEEK at $75 \mathrm{~S} / \mathrm{cm}$. At low humidity, even when the water availability was reduced, the increased free volume in the membrane allowed more water uptake within the S-TRP-PEEK membranes, which helps to maintain the hydration number at lower humidity, and facilitates the proton conductivity enhancement. Considering that PEMFCs should ideally operate at temperatures above the boiling point of water, wherein the humidity is low, S-TRP-PEEK membranes' high proton conductivity under low RH conditions are greatly desired [9].

SPAES-TRP membranes showed proton conductivities of $250 \mathrm{mS} / \mathrm{cm}$ at $94 \% \mathrm{RH}$ and $80{ }^{\circ} \mathrm{C}$. It was reported that the conductivity showed great dependence on relative humidity. This is typical behavior for hydrocarbon ionomer membranes due to less developed microphase separation than those of the perfluorinated ionomers [29]. At 34\% $\mathrm{RH}$ and $80{ }^{\circ} \mathrm{C}$, SPAES-TRP membranes showed proton conductivities of $4.5 \mathrm{mS} / \mathrm{cm}$. The excellent proton conduction of the SPAES-TRP membranes especially at low humidity may be explained by its excellent connectivity of proton paths and good water-holding capability of sulfonated TRP groups. Compared with Nafion ${ }^{\circledR}$ at similar relative humidity and temperature, SPAES-TRP membranes achieved higher proton conductivity in a wide range of humidity, which makes it a promising candidate for a more efficient PEM [10].

\section{Conclusion}

The latest development and applications of TRP-containing copolymers as PEM for PEMFC technology has been reviewed, and its critical properties have been discussed. Up until 2018, 102 research articles have been published on scientific literature platform SCOPUS ${ }^{\circledR}$ regarding the use of TRP for PEM application. In the present review, the addition of TRP in different types of composite membranes, which includes 4,4'-biphenol (BPSH) and sulfonated composite polymers such as sulfonated poly(ether ether ketone) (SPEEK) and sulfonated poly(aryl ether sulfone) (SPAES), and its critical properties with regards to PEM performance have been discussed. Additionally, the optimized percentages of TRP in the mentioned types of composite membranes have been also reviewed. Significant progresses on the 
development of TRP-containing copolymers in the past years and the current status of PEMFC technology have been reviewed. TRP-containing copolymers has been introduced as promising PEM materials to replace the industrial standard Nafion ${ }^{\circledR}$, owing to high water uptake, excellently low swelling ratio, good thermal and mechanical strength, and high proton conductivity in high temperature and low humidity conditions.

\section{Acknowledgement}

This work was financially supported by Ministry of Higher Education Malaysia (MOHE) through Fundamental Research Grant Scheme (FRGS/1/2019/TK07/UTHM/03/3) and Malaysia Research University Network (MRUN) grant scheme (Vot no.: K139 and 4L880). Authors also gratefully acknowledge Universiti Tun Hussein Onn Malaysia for the financial support through STG grant scheme (Vot. no: U654) and GPPS grant scheme (Vot no. U986).

\section{References}

[1] D. J. Kim, M. J. Jo, and S. Y. Nam, "A review of polymer-nanocomposite electrolyte membranes for fuel cell application," J. Ind. Eng. Chem., vol. 21, pp. 36-52, Jan. 2015.

[2] Y. Wang, K. S. Chen, J. Mishler, S. C. Cho, and X. C. Adroher, "A review of polymer electrolyte membrane fuel cells: Technology, applications, and needs on fundamental research," Appl. Energy, vol. 88, no. 4, pp. 9811007, 2011.

[3] N. Li and M. D. Guiver, "Ion transport by nanochannels in ion-containing aromatic copolymers," Macromolecules, vol. 47, no. 7, pp. 2175-2198, 2014.

[4] G. R. Whitnah, W. C. Borgeson, and H. E. Henjum, "Flugrocarbon Vinyl Ether Polymers," 1964.

[5] L. Zhang, S. R. Chae, Z. Hendren, J. S. Park, and M. R. Wiesner, "Recent advances in proton exchange membranes for fuel cell applications," Chem. Eng. J., vol. 204-205, pp. 87-97, 2012.

[6] J. Larminie and A. Dicks, Fuel Cell Systems Explained. 2013.

[7] H. Lade, V. Kumar, G. Arthanareeswaran, and A. F. Ismail, "Sulfonated poly(arylene ether sulfone) nanocomposite electrolyte membrane for fuel cell applications: A review," Int. J. Hydrogen Energy, vol. 42, no. 2, pp. 1063-1074, 2017.

[8] J. Aboki, B. Jing, S. Luo, Y. Zhu, L. Zhu, and R. Guo, "Highly Proton Conducting Polyelectrolyte Membranes with Unusual Water Swelling Behavior Based on Triptycene-containing Poly(arylene ether sulfone) Multiblock Copolymers," ACS Appl. Mater. Interfaces, vol. 10, no. 1, pp. 1173-1186, 2018.

[9] L. C. H. Moh, J. B. Goods, Y. Kim, and T. M. Swager, "Free volume enhanced proton exchange membranes from sulfonated triptycene poly(ether ketone)," J. Memb. Sci., vol. 549, pp. 236-243, 2018.

[10] F. Gong, H. Mao, Y. Zhang, S. Zhang, and W. Xing, "Synthesis of highly sulfonated poly(arylene ether sulfone)s with sulfonated triptycene pendants for proton exchange membranes," Polymer (Guildf)., vol. 52, no. 8, pp. 1738-1747, 2011.

[11] T. M. Swager, "Iptycenes in the design of high-performance polymers," Acc. Chem. Res., vol. 41, no. 9, pp. 1181-1189, 2008

[12] J.-S. Yang and J.-L. Yan, "Central-ring functionalization and application of the rigid, aromatic, and $\mathrm{H}$-shaped pentiptycene scaffold," Chem. Commun., no. 13, pp. 1501-1512, 2008.

[13] K. D. Kreuer, "On the development of proton conducting polymer membranes for hydrogen and methanol fuel cells," J. Memb. Sci., vol. 185, no. 1, pp. 29-39, 2001.

[14] M. Doyle, M. E. Lewittes, M. G. Roelofs, and S. A. Perusich, "Ionic conductivity of nonaqueous solvent-swollen ionomer membranes based on fluorosulfonate, fluorocarboxylate, and sulfonate fixed ion groups," J. Phys. Chem. B, vol. 105, no. 39, pp. 9387-9394, 2001.

[15] Y. Chen, R. Guo, C. H. Lee, M. Lee, and J. E. McGrath, "Partly fluorinated poly(arylene ether ketone sulfone) hydrophilic- hydrophobic multiblock copolymers for fuel cell membranes," Int. J. Hydrogen Energy, vol. 37, no. 7, pp. 6132-6139, 2012.

[16] S. Matsumura et al., "lonomers for proton exchange membrane fuel cells with sulfonic acid groups on the endgroups: Novel branched poly(ether-ketone)s," Am. Chem. Soc. Polym. Prepr. Div. Polym. Chem., vol. 49, no. 1, pp. 511-512, 2008.

[17] M. Litt and R. Wycisk, "Poly(arylenesulfonic acids) with frozen-in free volume as hydrogen fuel cell membrane materials," Polym. Rev., vol. 55, no. 2, pp. 307-329, 2015.

[18] A. Kusoglu and A. Z. Weber, "New Insights into Perfluorinated Sulfonic-Acid lonomers," Chem. Rev., vol. 117, no. 3, pp. 987-1104, 2017.

[19] L. C. H. Moh, "Enhancing Materials for Fuel Cells and Organic Solar Cells through Molecular Design," Massachusetts Institute of Technology, 2017.

[20] M. A. Hickner, H. Ghassemi, Y. S. Kim, B. R. Einsla, and J. E. McGrath, "Alternative Polymer Systems for Proton Exchange Membranes (PEMs)," Chem. Rev., vol. 104, no. 10, pp. 4587-4612, Oct. 2004.

[21] K. A. Mauritz and R. B. Moore, "State of understanding of Nafion," Chem. Rev., vol. 104, no. 10, pp. 45354585, 2004.

[22] S. S. Araya et al., "A comprehensive review of PBI-based high temperature PEM fuel cells," Int. J. Hydrogen Energy, vol. 41, no. 46, pp. 21310-21344, 2016.

[23] Y. Shao, G. Yin, Z. Wang, and Y. Gao, "Proton exchange membrane fuel cell from low temperature to high temperature: Material challenges," J. Power Sources, vol. 167, no. 2, pp. 235-242, 2007.

[24] K. Miyatake, Y. Chikashige, and M. Watanabe, "Novel sulfonated poly(arylene ether): A proton conductive 
polymer electrolyte designed for fuel cells," Macromolecules, vol. 36, no. 26, pp. 9691-9693, 2003.

[25] Shao K, Zhu J, Zhao CJ, Li XF, Cui ZM, Zhang Y, "Naphthalene-Based Poly(arylene ether ketone) Copolymers Containing Sulfobutyl Pendant Groups for Proton Exchange Membranes," J. Polym. Sci. Part A Polym. Chem., vol. 47, pp. 5772-5783, 2009.

[26] S. Luo et al., "Highly CO2-Selective Gas Separation Membranes Based on Segmented Copolymers of Poly(Ethylene oxide) Reinforced with Pentiptycene-Containing Polyimide Hard Segments," ACS Appl. Mater. Interfaces, vol. 8, no. 3, pp. 2306-2317, 2016.

[27] N. T. Tsui, L. Torun, B. D. Pate, A. J. Paraskos, T. M. Swager, and E. L. Thomas, "Molecular barbed wire: Threading and interlocking for the mechanical reinforcement of polymers," Adv. Funct. Mater., vol. 17, no. 10, pp. 1595-1602, 2007.

[28] A. S. Badami, O. Lane, H. S. Lee, A. Roy, and J. E. McGrath, "Fundamental investigations of the effect of the linkage group on the behavior of hydrophilic-hydrophobic poly(arylene ether sulfone) multiblock copolymers for proton exchange membrane fuel cells," J. Memb. Sci., vol. 333, no. 1-2, pp. 1-11, 2009.

[29] K. Nakabayashi, T. Higashihara, and M. Ueda, "Highly sulfonated multiblock copoly(ether sulfone)s for fuel cell membranes," J. Polym. Sci. Part A Polym. Chem., vol. 48, no. 13, pp. 2757-2764, 2010. 